\title{
DE MESÍAS, PACHACUTIS Y PROFETAS. EL APOCALIPSIS O EL DISCURSO DE LA CONTINGENCIA EN EL PERÚ*
}

\author{
Lucero de Vivanco \\ Universidad Alberto Hurtado \\ lvivanco@uahurtado.cl
}

RESUMEN / ABSTRACT

Frente a la expandida presencia del imaginario apocalíptico en la narrativa de ficción en el Perú, este artículo muestra que el apocalipsis también ha sido evocado por discursos "serios" o no ficcionales, fundamentalmente para interpretar las dimensiones de lo colectivo en el Perú, es decir, los aspectos relacionados con la contingencia política y social. En este marco, el artículo revisa una serie de acontecimientos políticos y el ensayo de interpretación de la realidad nacional, Réquiem por Perú, mi patria, de Herbert Morote.

PALABRAS ClaVE: apocalipsis, imaginario, literatura peruana, discurso público, pachacuti.

Facing the pervasive presence of an apocalyptic imaginariness in Peruvian narrative fiction, this article shows that the Apocalypse has also been evoked by "serious" or non-fictional discourses, primarily in order to interpret issues related to social and political contingency. From this position, the article reviews a series of political events along Herbert Morote's Réquiem por Perú, mi patria, a literary essay that interprets national reality.

KEY WORDS: Apocalypse, imaginariness, Peruvian literature, public discourse, pachacuti.

Este artículo ha sido producido en el marco del proyecto FONDECYT 11100059, "Los imaginarios de la violencia: construcciones y representaciones del conflicto armado interno en la literatura peruana contemporánea", proyecto en el que la autora es investigadora responsable. 
Aún en la noche el Fuego alumbrará los mundos. Será el incendio purificador. ¡Oh! El esperado Apocalipsis, el Día del Yawar-Inti que no tardará en amanecer. ¿Quién no aguarda la presentida aurora?

Luis E. Valcárcel

Tempestad en los Andes

El año 2012, marcado por el término de la cuenta del calendario maya, es sin duda un año especial en relación con el imaginario de fin de mundo. Y es que en estos tiempos, parece que más que nunca somos testigos de una creciente inclinación a relacionar acontecimientos de todo tipo con alguna forma de apocalipsis inminente. Eventos climáticos y telúricos, desastres ecológicos, virus pandémicos, crisis económica global, terrorismo a gran escala, fanatismos religiosos o políticos, hambre, violencia, todo parece ser indicador de un pronto desenlace fatal. Las sociedades recogen y promueven este imaginario, lo que se hace evidente en la proliferación de manifestaciones culturales y artísticas con referencias apocalípticas, en especial, en la literatura y el cine.

Pero, aunque no se puede negar la intensificación del imaginario apocalíptico en la actualidad, su presencia como tal no supone novedad alguna. Desde siempre, las sociedades han tendido a interpretar su propio tiempo histórico como el elegido para el cumplimiento de las visiones proféticas del Antiguo Testamento y, especialmente, la visión de un cristiano exiliado en la isla griega de Patmos, el conocido Apocalipsis de Juan. Esta es una característica propia del imaginario apocalíptico: en todas las épocas, individuos, agrupaciones o sociedades han identificado a los protagonistas de la narración apocalíptica y a sus principales símbolos como efectivamente existentes y actuantes en el momento que les ha tocado vivir. De manera particular, el Apocalipsis de Juan reviste tanta importancia porque es, a juicio de Frank Kermode, el relato de sentido por excelencia en la cultura occidental, dada la concentración de expectativas radicales de transformación social y advenimiento de justicia. Al respecto, tanto Kermode como Lois Parkinson han subrayado la orientación teleológica de la estructura del apocalipsis como narración. Ésta supone el momento propio de la existencia humana como un período intermedio entre el Principio y el Fin, y asigna una ordenación temporal que orienta sus metas en relación con ese Fin imaginado y esperado, en el que debieran coincidir el término y la finalidad (dos acepciones de la palabra "fin") de modo de otorgar sentido a la totalidad de la estructura. Según esta tesis, el relato apocalíptico está fundado en la necesidad de los seres humanos de proyectar finales con sentido. 
El Perú no constituye una excepción. El imaginario apocalíptico, ampliamente difundido durante la Edad Media (y reiteradamente frustrado también), está presente en este país desde la llegada de los primeros españoles, quienes vieron en el continente americano un lugar posible para su cumplimiento ${ }^{1}$. El apocalipsis en el Perú ha sido, desde entonces, un modelo para construir la realidad -tanto lo posible como lo fáctico-así como también un paradigma para representarla. Por otro lado, cuando esta experiencia se ha narrado desde la perspectiva de los vencidos, ha sido vista como catástrofe y ha sido colmada de elementos andinos, particularmente los conceptos de pachacuti e inkarrí. Etimológicamente, pachacuti (pacha, tierra; cuti, inversión) significa "transformarse la tierra", "inversión de mundo" (Flores Galindo 40). Dentro de una concepción de tiempo circular, el acontecimiento de características catastróficas o pachacuti era seguido de una renovación total, y el mismo vocablo aludía al Inca en su rol de restaurador del nuevo periodo (Ossio). Por su parte, el mito de inkarrí o Inca-rey completa la noción de pachacuti. De acuerdo con este mito, se cree que la cabeza decapitada del Inca busca unirse con el resto de su cuerpo descuartizado y desparramado por el territorio andino, para reaparecer como inkarrí y restablecer el orden del imperio ${ }^{2}$.

En este contexto, la literatura peruana contemporánea exhibe una serie de ficciones que utilizan el imaginario apocalíptico para hacer referencia al contexto peruano ${ }^{3}$. La simbolización apocalíptica en estas novelas trae a la materialidad del texto fundamentalmente condiciones de existencia críticas, instaladas desde el choque cultural entre españoles e indios y prolongadas durante la República bajo un sistema de estado postcolonial. Al respecto, Parkinson ha señalado que el apocalipsis, en tanto género literario emanado

1 Véase el ya clásico estudio de John L. Phelan. El reino milenario de los franciscanos en el nuevo mundo. México: Universidad Nacional Autónoma de México, 1972.

2 Véase mi artículo "Entre demonios y pisadiablos", sobre imaginario apocalíptico en la Colonia y su continuidad en la literatura peruana contemporánea.

Por ejemplo, las novelas Crónica de San Gabriel y Los geniecillos dominicales de Julio Ramón Ribeyro; Redoble por Rancas, Garabombo el invisible, El jinete insomne, Cantar de Agapito Robles y La tumba del relámpago de Manuel Scorza; El zorro de arriba y el zorro de abajo de José María Arguedas; Pantaleón y las visitadoras, Historia de Mayta y Lituma en los Andes de Mario Vargas Llosa; Mañana, las ratas de José B. Adolph; Adiós Ayacucho de Julio Ortega; Dos señoras conversan, Un sapo en el desierto y Los grandes hombres son así. Y también asá de Alfredo Bryce Echenique; Rosa Cuchillo de Oscar Colchado; Neguijón de Fernando Iwasaki; Abril rojo de Santiago Roncagliolo; Radio Ciudad Perdida de Daniel Alarcón. 
de la Biblia, se caracteriza justamente por surgir en contextos de crisis social, causados por la persecución política o la intolerancia religiosa padecidas por el pueblo hebreo y los primeros cristianos. En concordancia con esta óptica, la novelas apocalípticas peruanas examinan y discuten diversos aspectos relacionados con los procesos de modernización, la capacidad representativa del Estado-nación, los antagonismos sociales, la exclusión, la discriminación de clase, el racismo y, especialmente en los últimos años, la violencia política en el marco de la guerra entre el Partido Comunista del Perú, Sendero Luminoso y el Estado peruano ${ }^{4}$. Todas estas materias pueden considerarse factores causantes de crisis.

Sin embargo, el imaginario apocalíptico y la literatura peruana no solo se articulan hoy en día en función de los géneros ficcionales. Eso quiere decir que discursos "serios" también han echado mano de este imaginario para hablar y hacer una construcción del Perú de una manera, si cabe decirlo así, menos mediada. Y es aquí donde este artículo quiere poner el foco: me propongo mostrar que el apocalipsis ha sido uno de los imaginarios que con insistencia ha sido evocado desde el discurso público para interpretar las dimensiones de lo colectivo en el Perú, es decir, para representar aquellos aspectos relacionados con la contingencia política y social. Con este propósito, el artículo se divide en dos apartados. En el primero, mostraré algunos ejemplos de la presencia del imaginario apocalíptico en el ámbito de la política en el Perú, principalmente plasmados en medios de prensa escritos y digitales. En el segundo, analizaré el ensayo testimonial, Réquiem por Perú, mi patria, de Herbert Morote, estableciendo la tradición del ensayo apocalíptico en el Perú.

\section{DE MESÍAS Y PACHACUTIS}

En el alma de la multitud, cuyos adelantados mendicantes pordiosean en pleno Jirón de la Unión, está profundamente arraigada, diríamos que casi amalgamada con ella, la certeza de que súbitamente puede abrírsele a uno cualquiera el camino de la fortuna.

Sebastián Salazar Bondy Lima la horrible

$4 \quad$ Véase de Vivanco, Fabry y Logie. 
Un recorrido por el centro de Lima un mediodía cualquiera es una experiencia que pone al visitante en contacto con Dios y con el diablo. La visita al interior de una de las iglesias coloniales constituye un verdadero viaje a un pasado con olor a santidad. Altares barrocos y pinturas de vírgenes, santos y ángeles atiborran las paredes del templo. A pesar de ser un día cualquiera, se está celebrando misa y no faltan fieles que siguen la liturgia librito en mano. Otros se arrodillan para la oración diaria con un rosario o apoyando la frente sobre los nudillos entrelazados. El que menos, entra para persignarse frente al altar o para hacer una reverencia solemne ante su imagen de devoción más preciada. Aún se ven señoras con mantilla reconociéndose mudamente como miembros de una misma fe. Todo esto sucede en un interior penumbroso, entre cirios encendidos y olor a palo santo.

En el exterior, otra es la realidad: bulle un mundo plural y heterogéneo que no recuerda o recuerda de muy distinta manera la sacralidad de las iglesias y que está conformado por ciudadanos que se desplazan con prisa esquivando comerciantes o marchas sindicales, por artistas callejeros y artesanos que intentan captar la atención del peatón, por turistas y “cambistas" de dólares, por autos oficiales que transitan en caravana o taxis-mini que tienen en la bocina su único recurso de promoción, por oficinistas o desempleados y por escolares que entran y salen de las catacumbas del Convento de San Francisco o del Museo de la Inquisición. Pero también circula por las calles de Lima el que espera con disimulo la oportunidad para la estafa o el robo, el narcotraficante o el militar impune, el terrorista arrepentido o en receso, el juez o el fiscal corrupto. A pesar de que sigue oliendo a palo santo, lo que predomina es el olor a chifa o a comida criolla. En este entorno, estratégicamente centrada, la Plaza Mayor de Lima exhibe dos imponentes edificios que representan lo mejor y lo peor de estos mundos: la Catedral de Lima y el Palacio de Gobierno.

Por la Casa de Pizarro, como también es conocido el Palacio de Gobierno, han pasado todos los presidentes del Perú -algunos elegidos democráticamente y otros impuestos desde el cuartel militar-y han aspirado a pasar muchísimos más. Harían falta muchas páginas para dar cuenta de la complejidad de los vínculos entre la vida política en el Perú y las creencias religiosas populares, lo que no es posible en este lugar. Sin embargo, sí se pueden dar algunas pinceladas al respecto, especialmente en lo que se refiere a la forma en que ciertos personajes públicos recientes han refrescado motivos relacionados con la salvación del pueblo y el elegido a procurarla, la $f e$ en el destino, la esperanza en el cambio, la promesa de justicia, cualidades todas ellas que participan del imaginario apocalíptico. 
En términos generales, la dimensión pública de la sociedad peruana parece exhibir todavía huellas de un sentimiento mesiánico, según sugiere, por ejemplo, la vertiginosa rapidez con la que algunos líderes han pasado del casi total anonimato al sillón presidencial o el que algunas elecciones hayan reclutado a más de veinte candidatos, dejando ver la importancia que se otorga a la persona por sobre la ideología ${ }^{5}$. La mayoría de ellos hizo ofrecimientos sustentados en el deseo y la esperanza de las masas más que en un proyecto de mediano y largo plazo y un programa concreto para su cumplimiento. Es decir, se encumbraron no a partir de una proyección del presente hacia el futuro, como sería el caso de un plan de gobierno, sino a partir del anhelo de que el futuro irrumpa en el "ahora" (o un supuesto pasado mítico-utópico retorne) para dar cumplimiento a la compensación que el pueblo peruano "merece" y "espera". Por lo tanto, no solo la velocidad con que algunos líderes se apropiaron o estuvieron a punta de apropiarse del sillón de Pizarro ha sido una constante, sino también el aprovechamiento de alguna condición personal que permitiera la identificación del candidato con los más desposeídos.

En este sentido, más de un outsider ha capitalizado el descontento de los habitantes del Perú, "favorecido" por la corrupción y la violencia, por el desentendimiento de la clase política con respecto a las necesidades de los más carenciados y por la ineficiencia tanto de las instituciones y políticas públicas como de las personas que están a cargo de ellas. De esta manera llegó en 1990 a la cima política Alberto Fujimori (apodado "el chino", a pesar de su origen japonés), que sacó un $20 \%$ en la primera vuelta y un $60 \%$ en la segunda, liderando un movimiento denominado "Cambio 90". También estuvo a punto de llegar a esa misma cima en el 2006, reivindicando un discurso fuertemente etnocentrado y fundando el "Partido Nacionalista Peruano", un militar con un nombre crucial apocalípticamente hablando: Ollanta (en quechua: "el guerrero que todo lo mira") Moisés (el primer profeta bíblico) Humala.

Las elecciones del 2006 no favorecieron a Ollanta Humala con la presidencia, pero sí lo hicieron las del 2011, en las que tuvo que enfrentarse

Ver Aranda et al. Del regreso del inca a Sendero Luminoso: violencia y política mesiánica en Perú. Aunque el estudio no aporta mucho en términos interpretativos, tiene el valor de establecer una línea de continuidad histórica en este tema.

Son elocuentes también los nombres de algunos de estos partidos o agrupaciones. 
al clan Fujimori, esta vez en la figura de Keiko, hija de Alberto Fujimori, quien está condenado a 25 años de prisión por crímenes contra la humanidad. La necesidad de elegir en la segunda vuelta electoral entre Keiko -quien reivindicaba el fujimorismo y relativizaba el autoritarismo, la criminalidad y la corrupción del régimen de su padre- y Humala -quien como militar retirado exhibía una hoja de vida poco clara en cuanto al respeto de los principios democráticos y los derechos humanos ${ }^{7}$, y promulgaba un gobierno de inclusión social, lo que podía leerse como el fin de los privilegios de un sector poderoso dentro de la sociedad peruana- generó entre los electores una polarización política que se expresó redundantemente en términos apocalípticos. El rol de los medios digitales y de la prensa escrita fue fundamental en la difusión de esta radicalización dentro del imaginario del apocalipsis, los que atribuyeron la "destrucción" o la "demonización" a uno u otro candidato, según los intereses ideológicos, políticos o económicos desde donde se enunciara la interpretación. Aparecieron así, durante la campaña electoral y los primeros meses de gobierno, titulares tales como: "Apocalipsis Now: lo que se viene tras la primera vuelta", "Los cuatro jinetes del Apocalipsis"9, "Se viene Apocalipsis en la guerra sucia electoral"10 "Gabinete del Apocalipsis"11, "Contraorden: ya no habrá Apocalipsis"12.

7 Humala fue, como miembro de las Fuerzas Armadas, combatiente contrasubversivo y vinculado a violaciones de derechos humanos. También participó en un levantamiento militar contra el régimen de Fujimori en el año 2000.

8 http://blog.pucp.edu.pe/item/129900/apocalipsis-now-lo-que-se-viene-tras-laprimera-vuelta.

9 http://lamula.pe/2011/04/30/los-cuatro-jinetes-del-apocalipsis/roviamo. Dice en el blog: "En la campaña de la segunda vuelta los grandes intereses mercantilistas aliados con la corrupción, ha[n] reclutado a una serie de escribidores y comentaristas de radio y TV para actuar contra el candidato que está pidiendo mayor inclusión social [Humala], aumentar los impuestos a la[s] sobreganancias (sic) mineras para ayudar a los pobres, darles una pequeña pensión a los desposeídos, luchar contra la corrupción y otras medidas en favor del pueblo ... Las personas escogidas para esta campaña, son comparables a los Jinetes del Apocalipsis".

10 http://www.cronicaviva.com.pe/index.php/ciencia-y-tecnologia/tecnologia/20339se-viene-apocalipsis-en-la-guerra-sucia-electoral. Dice en la página: "los estrategas de la desinformación no aceptan su clamorosa pérdida de credibilidad y ahora preparan la batalla final del Armagedón, el Apocalipsis en esfuerzo desesperado para derrotar a Humala".

11 http://www.larepublica.pe/columnistas/el-diario-negro/gabinete-del-apocalipsis23-07-2011. Dice el columnista de La República: "Convendría advertir que, de momento, ni Ollanta Humala ni su gabinete son los agentes del Apocalipsis que tanto se temió".

$12 \mathrm{http}: / / \mathrm{www} \cdot$ revistaideele.com/content/contraorden-ya-no-habr\%C3\%A1-apocalipsis. 
Pero no solo los titulares fueron explícitamente apocalípticos. La "sensación de final" y "peligro inminente" sedimentaron realmente en los contenidos de las interpretaciones de la contingencia política del momento, tanto en términos de Keiko Fujimori como de Ollanta Humala. Sobre la candidatura de Keiko, por ejemplo, aparece este comentario que lleva por título "Apocalipsis Keiko":

Votar por Keiko es una trágica involución. Es votar por el pasado más negro de la República. Es premiar el robo y el asesinato como armas del poder. Es devolvernos al cinismo y la mentira. Es encontrarnos de nuevo a Montesinos suelto en plaza. Es regresar a los escuadrones de la muerte y a Martín Rivas ${ }^{13}$ escapando por una ventana del congreso para no ser investigado. Votar por Keiko es volver a ver un presidente paseando entre cadáveres de terroristas ajusticiados ilegalmente. Es retornar al baile del Chino trasladando la carceleta de la DIROES ${ }^{14}$ al salón dorado del palacio de gobierno. Elegir a Keiko es profundizar el desprecio eterno a las madres esterilizadas por su condición de pobres. Es ver más campos degradados por las mineras, más sueldos carcomidos por los services. Es el gas a 40 soles en Cusco y el consorcio Camisea robándose la riqueza de todos los peruanos ${ }^{15}$.

Y sobre la candidatura de Humala, un conocido y polémico periodista escribe "Triage para evitar un suicidio"16:

Personalmente, considero muy trágico para el país que Humala esté, por ahora, liderando la encuesta que presentamos. Esto sólo va a traer desazón entre los agentes económicos y puede hasta frenar en seco el crecimiento económico que venía tan boyante este año, pues las inversiones en marcha posiblemente se congelen desde hoy hasta ver

13 Martín Rivas dirigió el llamado "Grupo Colina”, "escuadrón de la muerte" que actuó durante diez años en la lucha antisubversiva. Se le atribuyen numerosas masacres y violaciones a los derechos humanos. Véase CVR, Tomo VII ("Las desapariciones de los estudiantes de la Universidad Nacional del Centro").

14 Dirección de Operaciones Especiales de la Policía Nacional del Perú. Lugar donde cumple condena Alberto Fujimori.

$15 \mathrm{http} / /$ rodrigonunezcarvallo.blogspot.com/2011/06/apocalipsis-keiko.html. Rodrigo Núñez Carvallo, narrador, pintor y bloggero peruano.

16 Explica el propio autor, Aldo Mariátegui, el significado del título de su artículo: "Triage es un galicismo que usan los médicos y militares como pauta extrema para concentrar recursos que en algún momento son muy escasos para dedicarlos solamente a los pacientes que tengan más posibilidades de salvarse. Ya los votantes estamos en tiempo de triage". 
quién ingresa a la segunda vuelta. Si el chavista lo consigue, pues vamos a tener dos meses de economía parada hasta que el ballotage defina al ganador. Y si Humala triunfase finalmente, pues no quiero ni pensar en el Apocalipsis económico que tendríamos; retrocederíamos al modelo velasquista y tiraríamos al tacho todo lo tan penosamente ganado desde la década de los 90. Así Humala, como el ecuatoriano Lucio Gutiérrez, termine dando una vuelta en $U$ en cuanto a su rojísimo ideario económico (algo muy improbable. ¡Tendría hasta que divorciarse de la mucho más roja Nadine!), al mercado le tomaría mucho tiempo aprender a confiar en él, además de que sería prisionero de una bancada congresal propia, que esta vez anda repleta de ultras ... "cochebomba" y otros que sólo saben destruir ${ }^{17}$.

Es interesante ver cómo en ambos casos se proyectan visiones escatológicas del futuro vinculadas, a su vez, a circunstancias políticas del pasado: al régimen de Alberto Fujimori, en el primer caso, y al gobierno militar de Juan Velasco Alvarado, en el segundo. Se establece la enunciación, entonces, como momento intermedio entre un principio y un fin; un tiempo crítico, especial; un tiempo kairos $^{18}$, que sustenta una expectativa clara y determinante con respecto al final, y la certeza de que, por muy distante que se vislumbre la presencia del fin, éste llegará ineluctablemente (Kermode). Y dado que la visión es pesimista, la concordancia entre pasado, presente y futuro se orienta más bien al sentido de un sinsentido. La distopía apocalíptica anunciada, por lo tanto, es compartida, aunque difiere el carácter de su concreción.

Pero no siempre las proyecciones de futuro en la política peruana se entroncan con pasados eventualmente distópicos. Dejando atrás la última contienda electoral, vuelvo al año 2000 (cambio de milenio y, como tal, año simbólicamente apocalíptico también) para referirme a uno de los casos más emblemáticos con respecto a la circulación del apocalipsis en el dominio público. Se trata de Alejandro Toledo, outsider como pocos (de fisonomía indígena educado en Harvard), que encabezó en el año 2000 el movimiento "Perú Posible" para luchar contra la ilegitimidad de la tercera elección consecutiva de Alberto Fujimori. El 28 de julio de ese año (efeméride de la independencia nacional, dicho sea de paso) convocó en Lima a la "marcha

$17 \mathrm{http} / /$ diariocorreo.pe/m/columna/1515/triage-para-evitar-un-suicidio/.

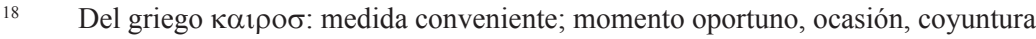

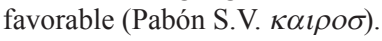


de los cuatro suyos" -nombre que toma de la división regional del imperio incaico- en la que proclama el siguiente discurso:

Pachakutiq ¡vive! ¡vive! Yo no tengo vergüenza de ser un cholo terco. La fuerza de nuestro Pachakutiq me guía, hace 50 años salí de mi pueblito con una nueva esperanza como ustedes, hoy les hablo no como doctor de la University de los EE. UU., sino como su hijo, convertido en un new Pachakutiq. De corazón les digo; yo sé la vida del pobre, de cuánto sufre, y cuántas veces ha llorado en silencio. Y como descendiente de los incas declaro la guerra mortal a nuestros opresores, mírense, nos ha insultado, se ha adueñado de nuestra casa y nos ha llevado a la somnolencia total, y hoy como descendiente de Pachakutiq no dejaremos humillarnos, no permitiremos que un chino cochino tome el poder. Esta mascaypacha sagrada en mi cabeza, es testigo de este día trascendental, padre, madre, hijo, hija, pueblo de mis entrañas, convoco al Perú profundo en nombre de Pachakutiq a la gran marcha de los cuatro suyos (Giménez Micó 6).

Como puede verse, Toledo no apela a una distopía, sino a la vitalidad de la utopía andina. A través de ella, actualiza el sentido restaurador del concepto pachacuti, arrogándose para sí mismo la función del Inca encargado de la renovación. Desde la hibridez construida para su propia persona (descendiente de incas con apellido de virrey, experiencia de pobre y doctor de la University), busca identificarse tanto con el "Perú profundo" de los Andes (el de José María Arguedas) como con el pueblo empobrecido de la capital. Pero, a diferencia de sus compatriotas, cuenta con el "excedente" de la University, lo que le da la autoridad para llevar la mascaypacha sagrada y guiar a su pueblo hacia cierta recuperación del espacio utópico del Imperio incaico, evitando que un foráneo (un chino cochino) se perpetúe en el poder.

El 29 de julio del año 2001, un día después de haber asumido la presidencia del Perú en los salones del Congreso, Toledo realiza un ritual en Machu Picchu, reproduciendo una ceremonia de toma de poder y de homenaje a los apus, tal como se realizaba durante el periodo incaico. Aquí lo acompaña Eliane Karp, su esposa, antropóloga belga y primera dama de la nación. Poco tiempo después del ritual de Machu Picchu, Karp explica que

la ceremonia de Machu Picchu marcó el inicio de una nueva etapa en el Perú. Fue un acto simbólico que reivindicó el Perú de Todas las Sangres. ... Por primera vez, un Jefe de Estado realizó el ritual andino del Hatun Haywa en las alturas del milenario Santuario. Dos sacerdotes 
andinos rindieron tributo e hicieron el pago a la Pachamama y a los Apus. El lado profundo del acto de juramentación del Presidente Toledo develó el propósito del mandatario de identificarse con la tradición del mundo andino que camina hacia la modernidad y se mantiene invencible a lo largo de 500 años, a pesar de los muchos esfuerzos por destruirla. Lo hizo explícito el Presidente de la República al formular en su discurso "El Perú busca ser competitivo en un mundo global, pero se halla anclado en las raíces de su historia" ( $\mathrm{s} / \mathrm{n})$.

En estas declaraciones, Karp asume el discurso pedagógico de la antropóloga antes que el de primera dama de la nación. Desde su saber epistémico, vincula la ceremonia de Machu Picchu con el discurso del Pachakutiq y la marcha de los cuatro suyos convocada anteriormente por Toledo, para reforzar el rol mesiánico del nuevo jefe de estado. En relación con lo anterior, conviene recordar que, en su libro Historia y etnología de los movimientos mesiánicos, María Pereira de Queiroz define al mesías como el mensajero divino que tiene por función "enderezar los entuertos" de una "colectividad descontenta u oprimida" e instaurar en el mundo una sociedad perfecta (22), características que parecen semantizar tanto el discurso de Toledo como la ceremonia del Hatun Haywa. Explica Pereira, además, que este "jefe sagrado" debe ser suficientemente descrito para que los fieles puedan reconocerlo con claridad (21), tarea didáctica que aparentemente está asumiendo Eliane Karp. Por otro lado, el sesgo hibridador se manifiesta en ella también: desde la tercera persona propia de su origen belga y su posición de autoridad letrada, apela al Perú profundo y a la convivencia armónica de "todas las sangres" (otra vez Arguedas) para vincular aspectos tradicionales de la cultura andina con el mundo competitivo y global de la postmodernidad.

Como corolario, quisiera agregar que no solo los que quisieron legitimar su poder en el sillón de Pizarro, sino también los que lucharon contra él, han mostrado preocupación -consciente o no- por su perfil mesiánico o apocalíptico. En La cuarta espada de Santiago Roncagliolo, libro en el que el autor recompone la historia de Sendero Luminoso a través del perfil biográfico de su líder Abimael Guzmán, se ofrece un dato que, aunque no confirmado, es elocuente del imaginario que gira en torno al también conocido por sus camaradas como "presidente Gonzalo". Dice Roncagliolo:

en su partida de nacimiento, Abimael figura con el nombre de Abismael. ... así se llamaba su padre, pero el hijo borró la s en sus documentos de adulto para tomar el nombre de uno de los jinetes de[1] Apocalipsis. 
En cambio, el informe de la Marina dice exactamente lo contrario: que eliminó la letra para tener un nombre menos apocalíptico (43).

\section{DE PROFETAS Y APOCALIPTISTAS}

Los caballos del Apocalipsis galopan a sus anchas por nuestro país. Esos briosos animales aplastan con sus pezuñas a cuanto habitante se ponga al frente. No son nuestros afeminados caballos de paso o los esmirriados caballitos serranos. Lo que enfrentamos en esta época son los recios caballos de los bárbaros atilas que nos profetizó César Vallejo, que vienen montados por los heraldos negros que nos manda la muerte.

\section{Herbert Morote \\ Réquiem por Perú, mi patria}

Dentro de lo que podría denominarse el canon de las letras peruanas del período republicano, hay al menos dos textos que merecen plantearse como antecedentes del Réquiem por Perú, mi patria (1992) de Herbert Morote. Esto es, dos textos que recodifican el imaginario apocalíptico en un ejercicio discursivo que pretende ser no ficcional. Uno de ellos es el ensayo inaugurador del indigenismo de Luis E. Valcárcel, Tempestad en los Andes (1927). El tono con que Valcárcel anuncia el resurgimiento del "nuevo indio" es amenazante y subversivo respecto de la opresión histórica impuesta a la raza "keswa", y asocia una naturaleza desquiciada y agónica a la proclama del verdadero ser del indio y del arribo de una justicia postergada. Mario Vargas Llosa ha afirmado que "la tormenta que anuncia es apocalíptica [y] mesiánica"(68) y José Carlos Mariátegui, en el prólogo que precede a la Tempestad, ha aseverado que"la empresa de Valcárcel en esta obra ... no es de profesor sino de profeta. No se propone meramente registrar los hechos que anuncian o señalan la formación de una nueva consciencia indígena, sino traducir su íntimo sentido histórico, ayudando a esa consciencia indígena a encontrarse y revelarse a sí misma" (7-8). El otro texto es Lima la horrible (1964) de Sebastián Salazar Bondy. En este ensayo, Salazar Bondy destruye el fantasma de la "Arcadia Colonial", por medio de la desmitificación minuciosa y documentada de una serie de lugares comunes provenientes del costumbrismo criollista. En este sentido, Valcárcel cumple la función de "revelar" una "verdad" concerniente a Lima, ciudad que presenta con crudeza, sin los espejismos nostálgicos del pasado virreinal, decretando el fin de este imaginario. En términos lacanianos, 
propone una verdad sobre Lima que descompleta la totalidad del saber; que desfamiliariza dicho saber (Ubilluz 67).

El Réquiem por Perú tiene de ambos: el tono subversivo, las imágenes perturbadoras, la necesidad de justicia, la revelación. Y comparte con ellos también la categoría que hace posible las características anteriores: la del narrador apocaliptista, la del profetismo. Como profetas, como apocaliptistas, estos autores hablan en nombre de una verdad que debe ser descubierta y explicada a sus contemporáneos: el mundo indígena, en el caso de Valcárcel; la ciudad de Lima, en el de Salazar Bondy; y el Perú en su conjunto, en el de Morote ${ }^{19}$. Se desempeñan como críticos y denunciadores de su propio tiempo, como opositores de las prácticas dominantes (Parkinson). Se encarnan como figuras de subversión dentro de la historia oficial que les ha tocado vivir, en la medida en que vaticinan la inversión del mundo, que pronostican la justicia radical y definitiva, que desarman los saberes anquilosados por los poderosos, que predicen el pago de los que han abusado, perseguido, dominado, y la compensación de los sufrientes, de los débiles.

La lectura que propongo del Réquiem por Perú, mi patria, por lo tanto, debe considerar, en primera instancia, el lugar de enunciación planteado en el texto por su propio autor. En este sentido, este ensayo nos pone en contacto con una de las formas simbólicas con las que se percibe y siente la nación (el "mi patria" del título) y, como forma simbólica, con ese saber imaginario que incorpora los conocimientos provenientes del dato estadístico y teórico, pero también los saberes que proceden de los mitos, las creencias y los afectos ${ }^{20}$. Para calibrar correctamente esta última afirmación, conviene hacer algunas precisiones con respecto a la enunciación del texto y a su recepción. Lo que da origen a su escritura, según declara el autor en las notas previas a la primera edición, está ligado a una experiencia vital: después de veinte años de vivir fuera del Perú, Morote decide volver definitivamente $\mathrm{y}$, en una visita preparatoria, según sus propias palabras, "me di cuenta de que mi patria había fallecido" (17). Es entonces que se propone auscultar el

19 Profeta: del griego "que habla por otros", "portador de la revelación divina", cuyo contenido "(ex-plica), correctamente y sin error” (Rahner S. V. Profeta).

$20 \quad$ Sobre el saber imaginario dice Patxi Lanceros: "Nos hallamos ante un tipo de conocimiento que escapa a la norma y a la hipótesis, que no es susceptible de rigurosa esquematización ni de plena explicación. Ese conocimiento se expresa en símbolos, dibuja horizontes de sentidos, juega con los miedos y las esperanzas colectivas y se organiza en discursos y prácticas no exentos de un cierto carácter conmemorativo y ritual” (63). 
cadáver (la alegoría corporal es constante en el texto) y como no encuentra "signos vitales" resuelve realizar una autopsia que le revele las razones del deceso. Este es el objetivo de su ensayo: buscar la verdad sobre la muerte de la patria y hacer el juicio final sobre los responsables de dicha muerte. Para ello necesita hacer una revisión totalizadora del Perú: extensísima en cuanto a sus temas, los que van desde la historia oficial y los símbolos patrios hasta su mitos y prejuicios, pasando por todo tipo de asuntos geográficos, políticos, económicos, sociales o culturales. Pero desde su perspectiva privada, como encontrar la patria muerta ha supuesto frustrar un proyecto de vida, la escritura del texto está impregnada de dolor y de rabia: "desearía que al leerlo duela, y duela tanto como a mí me dolió escribirlo" (14). "Han destruido la casita en la playa que nunca construí, a la que venían mis hermanos con sus hijos que nunca fueron. ¡Miserables! Han acabado con la gran familia que no constituí. ¡Incapaces!” (22).

Como puede apreciarse, el sentimiento de desengaño se manifiesta en la centralidad del "yo" y en el lenguaje con el que plasma su análisis, un lenguaje que se torna cada vez más descalificativo como prueba de un temple de ánimo exaltado y provocativo. En este sentido, el texto es muy difícil de situar genéricamente: oscila con inestabilidad entre el ensayo sociológico/ histórico y el testimonio. Y no obstante el autor parece ser una persona preparada (doctor en Ciencias Económicas por la Universidad de San Marcos, fundador de la Universidad de Lima, autor de diversos ensayos, obras de teatro y textos de ficción) y, no obstante, el propio Réquiem contiene mucha información fidedigna sustentando el discurso, la excesiva carga afectiva y subjetiva dificulta su recepción en términos de ensayo "serio".

Todas estas circunstancias dislocan el ensayo de Morote con respecto al lugar de donde tradicionalmente se espera que provenga un estudio sobre la "realidad nacional" y con respecto al lector modelo de los discursos de este tipo $^{21}$. Sin embargo, lo recolocan dentro de lo que se espera para el narrador del apocalipsis, género en el que "coinciden la muerte del individuo y el fin del mundo y, por consiguiente, los objetivos personales y comunales quedan inextricablemente unidos" (Parkinson 27). En este marco, es necesario dar fe a lo que el propio autor declara sobre su lugar de enunciación/representación y sus interlocutores: un peruano que ama a su patria ("¿quién soy yo, si no un

21 Sin embargo, aunque la crítica ignoró en gran medida la primera edición, ésta se agotó, aún estando disponible una versión en la web. 
peruano que tiene raíces profundas en su tierra, su familia, sus amigos y los sueños compartidos con ellos?", 13) y que cifra y descifra en representación de otros como él: "estoy describiendo lo que piensan los ciudadanos comunes y corrientes, las amas de casa, la gente del pueblo" (153). El lugar de enunciación de Morote se emparenta así con el del apocaliptista -según la definición de Parkinson-, quien es el narrador, pero también el receptor de los hechos que narra, por lo que debe hacer el doble ejercicio de descifrar (lo que oye y ve) y cifrar; de revelar y ocultar. Es un canal para la revelación, pero también nos entrega esa revelación desde su punto de vista personal ${ }^{22}$.

Este libro pone a nuestro alcance, entonces, un saber (que quiere ser) colectivo, producto de una percepción común y de un sentimiento que se asume compartido, al menos por un sector de la sociedad peruana; a partir -eso sí- de una representación de la nación imaginada hecha con cierta dosis de ingenuidad y simplificación. Un elemento estructural parece haber sido convocado a reforzar la idea de que este ensayo representa al "ciudadano común y corriente". A lo largo de todo el texto se han introducido unos breves diálogos que no están asignados a ningún personaje en particular pero que desde el anonimato van reforzando y/o comentando la exposición central del narrador. Por ejemplo, en relación con "la gente de mi patria", se establece la siguiente conversación:

-¿Hambre?

-Sí, es endémico.

$-i$ Guerra?

-Peor que eso, ahora la criminalidad está en su mayor gloria. Juro por mi madre que ninguna familia peruana se ha escapado de asesinatos, raptos, asaltos, violaciones, robos.

-¿Pestes?

-También. La que usted quiera ...

-¿Hay plagas?

-Sí, tenemos de todo ...

-¿Pero hay algo más?

-Por supuesto, hay muchísimo más pero si lo cuento se cansaría.

22 El mismo Juan recibe órdenes contradictorias en el Apocalipsis, como "Apenas se hicieron oír su voz los siete truenos, me disponía a escribir, cuando oí una voz del cielo que decía: «Sella lo que han dicho los siete truenos y no lo escribas»" (Ap 10:4). "Y me dijo: «No selles las palabras proféticas de este libro, porque el Tiempo está cerca»” (Ap 22:10). 
- ¿Se puede vivir así?

-No señor. Esto no es vida (58).

La dinámica de emisión y recepción del Réquiem arriba descrita se marca en el texto enfatizando las funciones emotiva y apelativa del lenguaje. Esto se hace especialmente evidente cada vez que el autor lamenta los efectos de la situación del Perú en su vida personal, pero también cuando se dirige directamente al destinatario de su texto, reclamándolo en una segunda persona plural y haciéndolo responsable de la debacle que ha sumergido al país en su propia muerte. Algunos de los subtítulos que se utilizan son elocuentes de lo anterior: "Un fuerte dolor mi pecho oprime, es el peso de mi raza" (22), "Yo puedo odiar" (25), “iMaldigo a los que me han robado el futuro!" (22), "Miserables patricidas" (26). La función apelativa, entonces, recae llena de Ira Dei sobre el cuerpo colectivo de los peruanos. El siguiente fragmento es un ejemplo del tono inculpador y mordaz mantenido a lo largo de todo el texto:

¡Compatriotas de mierda! Han acabado con poetas y albañiles, con artistas y verduleros, con científicos y obreros, con médicos y enfermeras, con gerentes y empleados, con místicos y prostitutas, con agrónomos y campesinos, con intelectuales y analfabetos, con empresarios y ambulantes. Ahora todo es ruin, ahora no hay esperanza para nadie. ¿Lo entienden? ¡Bestias!

Mis compatriotas son un asco. Por qué no gritarles ahora $¡$ Mediocres, incapaces! ¡Brutos, imbéciles! Han masacrado su propia Patria, que es la mía. Por eso no lloro de pena, sino de odio, de rabia contra ustedes. Han utilizado la violencia, la incomprensión, la mezquindad, el egoísmo, la corrupción, la envidia.

Mi única venganza es mi letra. ¡Oh, pueblo ruin! Allí tienen a nuestra patria asesinada. ¿Están satisfechos ahora? ¡Bravo! Hijos de la más grandísima ramera, lo lograron al fin y al cabo. ¡Repugnantes escatófagos! ¡Cómansela! Es lo único que falta (24).

El Réquiem por Perú juega con algunos de los sentidos más corrientes del apocalipsis -la devastación final, por ejemplo-y con algunas de sus imágenes más conocidas. La figura de "los caballos del Apocalipsis galopan[do] a sus anchas por nuestro país" (57), como se aprecia en el epígrafe de este apartado, es prueba de lo último. Sin embargo, el ensayo no se limita a la explicitación del apocalipsis sino que actualiza una serie de motivos que no necesariamente resultan tan evidentes. Uno de ellos es el texto como revelación, como mencioné más arriba. El autor se ha planteado dar a conocer 
a sus compatriotas lo que él considera la "Verdad" con respecto al Perú ${ }^{23}$. Justamente una de sus líneas argumentativas intenta demostrar la falsedad con la que ha sido escrita la Historia, cosa que el Réquiem se propone corregir: "en este Réquiem ayudaré a demoler sus falsos héroes, inocuos santos, malsanos mitos, y perversas costumbres. Talaré sin medida ni clemencia las frondosidad de nuestras corruptas instituciones y las estructuras de barro en la que se enlodan los gobernantes" (28). Por lo tanto, la revelación de la verdad únicamente será posible destruyendo el discurso de la Historia y sus mitos. En otras palabras, la situación escatológica del Perú (de término, de destrucción) será revelada en una acción que hace una escatología del relato de su historia (anulándola por su falsedad). Las ruinas del Perú se revelarán, entonces, en las ruinas del discurso histórico; y con la caída del relato caerá también su lenguaje. En este sentido, si la posibilidad de justicia viene por el ámbito letrado ("mi única venganza es mi letra"), se entiende el uso cáustico del lenguaje en el texto.

Recordemos que el lenguaje del Apocalipsis bíblico está altamente alegorizado, dado el doble ejercicio del narrador de descifrar y volver a cifrar, y que es por medio del lenguaje que el apocaliptista revela a sus contemporáneos el designio divino para la historia humana. El narrador bíblico muestra en su revelación la tiniebla pero también la luz, la catástrofe pero también la salvación y la esperanza futura. Sin embargo, el texto de Morote no admite ni luz ni salvación ni tampoco futuro. El Réquiem es solo tinieblas que se descubren tanto en lo revelado como en el lenguaje utilizado para la revelación, en el que por momentos suprime incluso el castellano. El Réquiem es solo destrucción, presente muerto, historia consumada, patria que “no podrá ser. ¡Jamás! ¡Kaput! ¡Finito! ¡Never again! ¡Nunca jamás!” (24).

Resulta curioso, sin embargo, por no decir contradictorio, que el narrador, al mismo tiempo que pretende desmitificar la historia, para lo cual destruye el presente y su lenguaje, se refiera nostálgicamente a un pasado idealizado y describa el futuro en los mismos términos. "Mi patria tenía fragancia a la flor de la canela que llevaba la guapa del valsecito, a colonia de mi bisabuela Etelgiva, a agua de Florida en la repisa del baño, a talco para bebés, a flores domingueras que llevaba a casa" (18), escribe con respecto al pasado. Y

23 Etimológicamente, Apokálypsis significa revelación. Conjuga la partícula de negación $a$ con la raíz kalypto (cubrir, ocultar), raíz que reconoce a la ninfa Calipso quien ocultó a Odiseo durante siete años (Parkinson 22). 
para referirse al futuro (aunque luego aclare que "estamos a años luz de que esto suceda") dice:

será una Patria donde la honradez sea una virtud a imitar. Donde el indio, o lo que quede de él, sea respetado. Donde el trabajo sea deseado. Donde la mentira sea mal vista. Donde el político sea probo ... En fin, si algún día mi Patria renace, se podrá exponer las ideas, por más absurdas que sean, con entera libertad, sin miedo a ser castigado o perseguido (272).

Algo equivalente sucede con el lenguaje. A pesar de ser brutal, todo el ensayo está concebido como una misa de réquiem, en particular, el Réquiem de Mozart. Por lo tanto, cada capítulo incorpora en su inicio un fragmento del texto litúrgico en latín (Introitos, Kyrie, Dies irae, Tuba mirum, Rex tremendae, Recordare, Confutatis, Lacrimosa, Offertorium Domine Iesu Christe, Offertorium Hostias, Sanctus, Agnus Dei, Lux aeterna), con su correspondiente traducción al castellano, y al final, un fragmento cuyo estilo reproduce el de la liturgia pero que conlleva la intensión sarcástica que comparte con el resto del texto. La cercanía entre la liturgia y el sarcasmo parece ambicionar la re-sacralización del lenguaje en ruinas. Así, por ejemplo, en la primera parte del capítulo "Terrorismo y crimen" aparece (transcribo únicamente la traducción al castellano):

\section{Offertorium. Domine Jesu Christe}

Señor Jesucristo, Rey de la gloria, libra las almas de todos los difuntos de las penas del infierno y del abismo sin fondo. Líbralos de las fauces del león a fin de que no los engulla y caigan en las tinieblas: Que San Miguel, tu portaestandarte, los lleve a la luz eterna: Que Tú le prometiste hace tiempo a Abraham y a su posteridad (191).

Y al final del mismo capítulo leemos:

\section{Offertorium. Domine Jesu Christe}

El León de la violencia cerró sus fauces, estamos engullidos y no podemos salir.

¿Dónde está San Miguel, tu portaestandarte, que no viene a salvarnos?, ¿con quién se ha entretenido? Cuando se reveló el arcángel Luzbel, 
¿organizó guerrillas o terrorismo? ¿Fue realmente la Soberbia el peor de sus pecados o quiso hacer algunos cambios estructurales en el Universo?

Pregunto, Oh Domine Jesu Christe, sólo por curiosidad (204).

La operación que pone bajo un mismo escenario lo sagrado y lo profano se hace también notoria cuando se actualiza otro de los motivos apocalípticos del texto: el juicio final. La búsqueda de la verdad propuesta en este ensayo tiene como correlato la exposición de los responsables de la muerte de la patria ante la "Verdad" y su "Gran Juez, El Que Sabe y Todo" (135), "El que Recuerda Todo" (126), "El de la Buena Memoria" (136). Los epítetos del enjuiciador, que se repiten sistemáticamente cada vez que se expone a uno de los gobernantes de la patria ante el tribunal, apelan todos a la memoria de la historia. La cuenta debe rendirse, entonces, ante su "Verdad". Una verdad ineludible, según Morote: en "algún momento de nuestra vida o muerte nos enfrentamos a la Verdad, esa verdad que es evidente, que no admite subterfugios ni paliativos" (123). Sin embargo, "no es Yahvé el que castiga, es la misma irresponsable sociedad putrefacta del Perú que se autoinmola con saña" (75). El gran pecado es, por supuesto, haber asesinado a la patria, lo que ha sucedido, por ejemplo, porque "no existe un 'PROYECTO DEL PERÚ' a debatir o compartir" (32) o por la falta de valores o por la corrupción de sus instituciones. Razones no faltan.

Como puede observarse, los motivos apocalípticos de la revelación y el juicio comparten un objetivo común: ambos apuntan a destruir la falsa historia del Perú. Uno y otro pretenden, por tanto, demoler la nación imaginada en todas sus facetas: ideológica, social, cultural. En esta línea, aunque la atribución de la culpa recaiga gruesamente sobre la sociedad peruana en su conjunto, el autor indaga más finamente para identificar a los responsables de este apocalipsis a partir de algunos rasgos identitarios de grupo, tipificados como el "LDM, veneno mortal" (64) y el "CDM, mordedura de ofidio" (70). El primero es el "limeñito de mierda", concepto que, a pesar del nombre, no se aplica únicamente a los nacidos en Lima ni a los habitantes de esta ciudad.

La identificación de este asqueroso sujeto es fácil: es todo aquel que pretende tener algo que no posee. No me refiero solamente a lo material y a lo social, sino más que todo a lo "intelectual". Pretendiendo, llega finalmente a creer que su situación familiar, racial, económica, profesional o meramente circunstancial (hasta el ridículo de presumir del barrio municipal donde vive) le da derecho a 
pitorrearse y despreciar al que está aparentemente debajo. El LDM se cree con derecho a transgredir todas las normas, costumbres valores de la sociedad y aun de la familia (65).

El segundo es el "criollito de mierda", que proviene del "criollismo" peruano degradado, y que define como "otro sujeto igualmente causante de los Días de Ira" (70). A diferencia del LDM que presume a voces su condición, el CDM es silencioso y actúa intentando pasar inadvertido.

El CDM quiere engañar a todo el mundo, sacar ventaja en cada oportunidad, desde escamotearse para conseguir un asiento al lado de la ventana sin importarle los ancianos o inválidos, hasta robar la misma cocaína que confiscó y venderla al mismo traficante que apresó. El criollito de mierda es el que se zampa en la cola, se queda con el cambio, arroja subrepticiamente cáscaras de plátano en la vía pública y no por ignorancia. Todo lo hace a escondidas, o a veces acompañado de otros "criollitos de mierda" igualmente falaces. Se cree más listo y pillo que el resto del mundo (70).

Pero no se trata de grupos aislados. El narrador deja claro que los LDM y CDM están esparcidos democráticamente por todo el Perú y que uno puede hallarlos en todos los estratos y clases sociales. Cada grupo tiene, también, su representante supremo: "Así como el cardenal Cipriani ${ }^{24}$ es el sumo pontífice de los LDM, Vladimiro Lenín Montesinos Torres ${ }^{25}$ es el más

$24 \quad$ Juan Luis Cipriani Thorne, Arzobispo de Lima desde 1999 y Primado del Perú. Primer miembro del Opus Dei en recibir el título de Cardenal en el 2001. A la muerte de Juan Pablo II, Cipriani fue uno de los "papables" como representante de la Iglesia Latinoamericana. Personaje sumamente controversial dentro de la sociedad peruana, fundamentalmente por realizar proselitismo político desde el púlpito aprovechando la situación de poder que le da ser el máximo representante de la Iglesia en el Perú, desde una posición ideológica contraria a las distintas agrupaciones defensoras de los derechos humanos. Véase CVR, Tomo III ("La iglesia católica y las iglesias evangélicas").

$25 \quad$ Asesor del jefe del Servicio de Inteligencia y del propio presidente del Perú durante el mandato de Alberto Fujimori. Actualmente cumple condena en una cárcel de alta seguridad en el Callao (la misma en la que se encuentra Abimael Guzmán), por razones que lo vinculan, entre otras cosas, a la acción de grupos paramilitares que se movilizaron ilegalmente contra el terrorismo, y a la extorsión de cientos de políticos y empresarios, lo que grababa en video sin conocimiento de los interlocutores, y que luego constituyó un escándalo conocido como "los vladivideos". Véase CVR, Tomo III ("La década de los noventa y los dos gobiernos de Alberto Fujimori”). 
bajo, rastrero, canalla y miserable de los criollitos de mierda" (73). No se trata, no obstante, de figuras repudiadas por la sociedad peruana sino, más bien, integradas a ella, para lo cual Morote tiene una explicación: "está en nuestra sangre" (74). El enlace instaurado, entonces, entre lo que pasa en el Perú y sus construcciones identitarias es directa: es una relación ligada a la sangre y, por lo tanto, planteada por Morote en términos esencialistas; apocalipsis e identidad peruana atados en sus genes y reforzada la cadena por su historia y su cultura. En este sentido, el apocalipsis forma parte del imaginario nacional y hasta de los símbolos que representan la imagen de la patria: el himno nacional plantea así una "apocalíptica apuesta: «[Somos libres] seámoslo siempre y antes niegue sus luces el sol». Es decir, que si faltamos a la promesa de mantenernos libres, aceptaremos un eclipse total por el resto de nuestros días" (33).

\section{PARA FINALIZAR...}

Y como todo llega a su término, propongo cuatro ideas para cerrar. Primero, la vigencia del imaginario apocalíptico en el lenguaje popular expresa, sin duda, un apocalipsis más inmanente que inminente, en el que se han instalado los "signos" sociales del fin pero no las acciones políticas rectificadoras ${ }^{26}$. Segundo, la porosidad de la frontera entre la "realidad" y la "ficción" en el ámbito del discurso público (sin problematizar por el momento estos dos términos), permite el tránsito sin trabas de las construcciones imaginarias de fin de mundo, las que se refieren a ambos espacios sin distinción de naturaleza. En otras palabras, la forma en que el discurso público actualiza el apocalipsis difumina la diferencia entra la realidad y la ficción. Tercero, el imaginario apocalíptico en el Perú es experimentado tanto en función de los hechos que constituyen la historia como en función de los discursos que la interpretan. Esto implica, creo yo, una sedimentación inconsciente del apocalipsis en la sociedad, sea que se manifieste con la fuerza creativa del imaginario social, según lo entiende Castoriadis ${ }^{27}$, sea que se presente para

26 Como consecuencia del no cumplimiento reiterado en la historia de las profecías de fin de mundo anunciadas en el Apocalipsis, según Kermode, el Fin deja de ser un hecho inminente para convertirse en un hecho inmanente.

27 Imaginario social entendido como el conjunto de significaciones imaginarias creadas autónomamente por una sociedad instituyente que, en el libre ejercicio de su autonomía, 
darle opacidad fantasmática a lo real, según lo entiende Žižek ${ }^{28}$. Por último, la riqueza del apocalipsis como constelación simbólica, por un lado, y la manipulación ideológica ligada a los intereses particulares de sus emisores, por el otro, hacen que este imaginario se exprese incluso en sus pares opuestos. Por ejemplo, el apocalipsis ha sido utilizado para mitificar pero también para desmitificar la historia, para levantar utopías pero también distopías, para evocar lo sagrado pero también lo profano, para rememorar al pasado pero también para proyectar el futuro. Esta poética apocalíptica en el Perú -llena de arte y maña, de pericia y versatilidad- hace esperable -y deseable- que, ante un verdadero apocalipsis, el país sepa cómo sobrevivir.

\section{BIBLIOGRAFÍA}

Aranda, Gilberto; Miguel Ángel López y Sergio Salinas. Del regreso del inca a Sendero Luminoso: violencia y política mesiánica en Perú. Santiago: Ril, 2009.

Castoriadis, Cornelius. Los dominios del hombre. Las encrucijadas del laberinto. Barcelona: Gedisa, 1998.

Comisión de la Verdad y Reconciliación (CVR). Informe final. Lima: CVR, 2003. Disponible en www.cverdad.org.pe.

De Vivanco, Lucero. "Entre demonios y pisadiablos. Imaginario apocalíptico en la literatura peruana”. Geneviève Fabry, Ilse Logie, Pablo Decock (eds.). Los imaginarios apocalípticos en la literatura hispanoamericana contemporánea. Bern: Peter Lang, 2010.

De Vivanco, Lucero, Geneviève Fabry, Ilse Logie. "Nuevas pautas para el estudio de los imaginarios (post)apocalípticos en la literatura hispanoamericana". Julio Ortega (ed.). Nuevos hispanismos. Para una crítica del lenguaje dominante. Madrid / Frankfurt: Iberoamericana / Vervuert, 2012.

Flores Galindo, Alberto. Buscando un inca: identidad y utopía en los Andes (Obras completas III-I). Lima: Sur Casa de Estudios del Socialismo, 2005.

Giménez Micó, José Antonio. “Imaginarios políticos en el Perú. ¿Entre el populismo andinista y el antipopulismo neoliberal? El caso Toledo”. Actas de Jalla 2006. Bogotá: CD virtual, 2006. 1-12.

González Vigil, Ricardo. “Alfredo Bryce: tres historias nostálgicas”. Los mundos de Alfredo Bryce Echenique (Textos críticos). César Ferreira e Ismael P. Márquez (eds.). Lima: Pontificia Universidad Católica del Perú, 1994. 295-297.

imagina sus propias formas de ser sociales, las que la cohesionan como sociedad y le dan su identidad.

28 La fantasía o el fantasma sería aquello que encubre lo real del deseo del sujeto y, más ampliamente, lo real del mundo y su horror, los antagonismos que recorren nuestra sociedad, la violencia, las guerras, el genocidio. 
Karp, Eliane y Linda Lema. "Multiculturalidad y racismo de la globalización". Realidad Social. Ottawa: Poetas Antiimperialistas de América, 2002. Disponible en: http://poetas. $\mathrm{com} / \mathrm{revista} / \mathrm{realidad} /$ acta_18.shtml.

Kermode, Frank. El sentido de un final. Estudios sobre la teoría de la ficción. Barcelona: Gedisa, 1983.

Lanceros, Patxi. "Conocimiento". Diccionario de Hermenéutica. Andrés Ortiz-Osés y Patxi Lanceros (dir.). Bilbao: Universidad de Deusto, 2006. 60-66.

Morote, Herbert. Réquiem por Perú, mi patria. Lima: Palao, 2004.

Ossio, Juan M., (ant.). Ideología mesiánica del mundo andino. Lima: Ignacio Prado Pastor, 1973.

Pabón, José. Diccionario manual griego-español. Barcelona: Vox, 1985.

Parkinson, Lois. Narrar el Apocalipsis. México: Fondo de Cultura Económica, 1996.

Pereira de Queiroz, María. Historia y etnología de los movimientos mesiánicos. México: Siglo XXI, 1969.

Phelan, John L. El reino milenario de los franciscanos en el nuevo mundo. México: Universidad Nacional Autónoma de México, 1972.

Rahner, Karl y Herbert Vorgrimler. Diccionario teológico. Barcelona: Herder, 1966.

Roncagliolo, Santiago. La cuarta espada. La historia de Abimael Guzmán y Sendero Luminoso. Buenos Aires: Debate, 2007.

Sagrada Biblia. Versión directa de las lenguas originales por Eloíno Nácar y Alberto Colunga. Madrid: La Editorial Católica, 1960.

Salazar Bondy, Sebastián. Lima la horrible. México: Era, 1968.

Ubilluz, Juan Carlos; Alexandra Hibbett y Víctor Vich. Contra el sueño de los justos: la literatura peruana ante la violencia política. Lima: IEP, 2009.

Valcárcel, Luis E. Tempestad en los Andes. Lima: Populibros peruanos, 1927.

Vargas Llosa, Mario. La utopía arcaica. José María Arguedas y las ficciones del indigenismo. México: Fondo de Cultura Económica, 1997.

Žižek, Slavoj. El acoso de las fantasías. Buenos Aires: Siglo XXI, 2005.

Medios digitales (en orden de mención)

http://blog.pucp.edu.pe/item/129900/apocalipsis-now-lo-que-se-viene-tras-la-primera-vuelta. http://lamula.pe/2011/04/30/los-cuatro-jinetes-del-apocalipsis/roviamo.

http://www.cronicaviva.com.pe/index.php/ciencia-y-tecnologia/tecnologia/20339-se-vieneapocalipsis-en-la-guerra-sucia-electoral.

http://www.larepublica.pe/columnistas/el-diario-negro/gabinete-del-apocalipsis-23-07-2011. http://www.revistaideele.com/content/contraorden-ya-no-habr\%C3\%A1-apocalipsis.

http://rodrigonunezcarvallo.blogspot.com/2011/06/apocalipsis-keiko.html.

http://diariocorreo.pe/m/columna/1515/triage-para-evitar-un-suicidio/. 